\title{
Effect of Implementing Nursing Guidelines on Nurses' Performance Regarding Complications of Nasogastric Tube among Critically ill Patients
}

\author{
Fatma Mohammed Attia ${ }^{\mathbf{1}}$, Manal Hamed Mahmoud ${ }^{2}$ and Nehal Mahmoud Abo El-Fadl ${ }^{\mathbf{3}}$ \\ (1) Clinical Instructor of medical surgical nursing, Faculty of nursing, Benha University, (2) Professor \\ of medical surgical nursing Faculty of nursing-Benha University and (3)Lecturer of medical surgical \\ nursing Faculty of nursing- Benha University
}

\begin{abstract}
Background: Nasogastric tube feeding is the most frequently used method of enteral feeding among critically ill patients and it is accompanied by some complications that can lead to increased morbidity and mortality. Aim of the study: Was to evaluate the effect of implementing nursing guidelines on nurses' performance regarding complications of nasogastric tube among critically-ill patients. Hypothesis: Nurses' performance regarding complications of nasogastric tube among critically-ill patients will be improved after implementation of the nursing guidelines than before. Design: Quasiexperimental research design was utilized in this study to achieve the aim of this study. Setting: The study was carried out in Intensive Care Unit at Benha University Hospital. Subjects: Convenient sample (60) nurses. Tools of data collection: Two tools were used, I: Self-administered questionnaire to assess nurses' knowledge regarding nasogastric tube and its complications, II: Observational checklist to assess nurses' practice during caring for patients with nasogastric tube and its complications. Results: The study revealed that nurses' knowledge and practice score regarding nasogastric tube pre guidelines implementation was (70\% and 53.3\%), mean score $(14.6833 \pm 5.85848$ and $131.2833 \pm 12.85920)$ which improved immediately post guidelines implementation $(93.3 \%$ and 95\%), mean score 36.6833 \pm 2.04601 and $271.5667 \pm 8.19749$ as $(\mathrm{p} \leq 0.001)$. Conclusion: Providing nursing guidelines has been shown to be effective on nurses' performance regarding complications of nasogastric tube among critically ill patients. Recommendation: In service education and training for nurses regarding prevention and management of nasogastric tube complications among critically ill patients.
\end{abstract}

Key Words: Nasogastric tube, Nursing Guidelines, Critically ill patients, Nurses' performance.

\section{Introduction}

The human body needs adequate nutrition of various food compositions for cellular function, metabolism, growth, activities, reproduction, health maintenance and recovery from illness or injury, in critically ill patients who are not able to feed through mouth, but the digestive system has the ability to digest food, enteral feeding is used (Jamshidi, Hejazi \& Mazloom, 2020). Nutritional guidelines have recommended that EN should be started within 24 to 48 hours of patients' admission to the intensive care unit or after the stability of the hemodynamic state, as it benefits the patients by decreasing catabolic response to injury and maintaining bowel mucosal integrity (Aziz \& Ali, 2020).

Nasogastric tube is inserted into the stomach through the nose when the enteral feeding is required for short period less than 4-6 weeks, defined as the delivery of nutrients through the nasal route down the throat, esophagus then into the stomach via a thin and soft feeding tube for providing nutritional support in patients who are unable to ingest food orally because of health issues or those with neurological swallowing disorders, upper GI obstruction, GI dysfunction or malabsorption (Xu et al., 2020). 
Good nutritional support is a primary nursing role. Therefore, nurses should have adequate knowledge and practice for caring patients with nasogastric tube feeding e.g. knowing indications, contraindications, complications of the use of nasogastric tube, making nutrition assessment, assessing of energy and nutritional requirements, inserting the NGT, confirming its placement, administering feedings, prefeeding readiness assessment, medication administration, tube lavage if required, monitoring or handling complications and tube removal when patient's condition improved (Rezaei et al., 2018). So, evidence-based protocols and scientific guidelines are recommended to guide nurses continuously (Mooi, 2018).

\section{Significance of the study}

Malnutrition in critically ill patients is a global public health problem with a prevalence of $40 \%$ to $60 \% .50 \%$ of patients have malnutrition before hospitalization from the pathology of a critical illness, while $70 \%$ of patients have malnutrition during hospitalization. Critically ill patients can't resume an oral diet which is a problem related to impaired gastrointestinal function as high gastric residual volume, the presence of diarrhea, vomiting and aspiration. The management of nutrition is delayed in $60 \%$ of critically ill patients and causes inadequate daily calorie target in $42 \%$ of these patients, these conditions affect body muscle, particularly the diaphragm, which is used for respiration and may become weak and atrophic that leads to decrease patients' ability for weaning mechanical ventilation, pressure sores, infections and increases mortality rate

(Koontalay, Sangsaikaew \& Khamrassame, 2020).

\section{Aim of the study}

This study aimed to evaluate the effect of implementing nursing guidelines on nurses' performance regarding complications of nasogastric tube among critically-ill patients.

\section{Research Hypothesis:}

Nurses' performance regarding complications of nasogastric tube among critically-ill patients will be improved after implementation of the nursing guidelines than before.

\section{Subjects and Methods \\ Design:}

Quasi-experimental study design was used in this study.

\section{Setting:}

The study was carried out in Intensive Care Unit (ICU) at Benha University Hospital, locates in second floor of the medical building, it contains three rooms and four conters; each room has two beds, each conter contains four beds and it has semiconscious and unconscious critically ill patients.

\section{Subjects:}

The subjects of this study included all available nurses (60) nurse (convenient sample)

\section{Tools for data collection:}

Tool I: Self-administered questionnaire for nurses

It aimed to assess nurses' knowledge regarding nasogastric tube and its complications, adapted from (Metwaly, Mohammed \& Mohammed, 2013) \& (Babapour et al., 2016). It consisted of two parts:-.

Part one: Nurses' demographic data, this part concerned with assessment of nurses' demographic characteristics. It composed of five questions related to age, sex, educational level, years of experiences and training courses.

Part two: Nurses' knowledge, this part designed to assess nurses' knowledge regarding basic concepts of nasogastric tube, indications, contraindications, feeding administration, medication administration and complications. It composed of 39 multiple choice questions.

The score distributed as: one mark for each correct answer and zero for incorrect answer the total score converted into percentage and graded as the following:-Below $75 \%$ graded as 
unsatisfactory level of knowledge. $75 \%$ and above graded as satisfactory level of knowledge.

Tool II: Observational Checklist for nurses' practice

It aimed to assess nurses' practice during caring for patients with nasogastric tube and its complications. It consisted of two parts:-

Part one: Aimed to assess routine nursing care as: Nasogastric tube feeding administration and medication administration, adapted from

(Abdullah, Mohammed \& Ismai, 2014) (Willihnganz \& Clayton, 2016) \& (Cooper\& Gosnell, 2018).

Part two: Aimed to assess nursing care during nasogastric tube complications as mechanical, infectious and metabolic complications, adapted from (Blumenstein, Shastri \& Stein., 2014) \& (Lewis et al., 2017)

The score distributed as: one mark for each step correctly done, and zero for incorrectly done \& not done the total score converted into percentage and graded as the following:-

Below $85 \%$ graded as unsatisfactory level of practice. $85 \%$ and above graded as satisfactory level of practice.

\section{Content validity:}

The tools were reviewed by a panel of five experts from medical surgical nursing field at faculty of nursing Benha University to test the relevance, clarity of tools' content, comprehension, understanding, applicability and necessary modification was done accordingly.

\section{Tool reliability:}

The reliability for self-administered questionnaire that used to assess nurses' knowledge $=0.970$, reliability for observational checklist that used to assess nurses' practice $=$ 0.99 .

\section{Ethical considerations:}

- The aim of this study was explained to all nurses and they were reassured that all information was confidential and it was used only for their benefit and for research purpose.
- $\quad$ Nurses consent to participate in the study was obtained.

- Nurses were informed that they were allowed to choose to participate or not in the study and they had the right to withdraw from the study at any time.

\section{Pilot study:}

A pilot study was conducted on $10 \%$ of all nurses ( 7 nurses) from the total number of nurses (70) in order to test the clarity and applicability of the tools. Nurses included in pilot study are excluded from the main study

\section{Field work:}

All available nurses in the Intensive Care Unit during the time of data collection and agree to participate in this study was recruited into the study.

After the study protocol has been approved, an official permission was taken from the director of Benha University hospital after explanation of the purpose of the study. The study was conducted on phases as the following:

Assessment phase: Assessment of the nurses' knowledge through self-administered questionnaire (Tool I) and assessment of the nurses' practical skills through observational checklist (Tool II)

Planning phase: The guidelines developed by the researcher according to nurses' needs and deficiencies in their performance, teaching materials was prepared e.g. discussion, demonstration and booklet that helped in covering theoretical and practical information.

Implementation phase: The researcher gave the guidelines booklet to nurses immediately after data collection

Evaluation phase: The post test for nurses' knowledge through self-administered questionnaire (Tool I) and practice through observational checklist (Tool II) was done immediately after giving the nursing guidelines to them 


\section{Results}

Table (1) demonstrates that, $66.7 \%$ of the studied nurses' age was less than 25 years with a mean age of $23.82 \pm 2.20$ years, while $86.7 \%$ of them were females. Regarding educational level, $90.0 \%$ of the studied nurses graduated from technical institute of nursing. As regard nurses' years of experience, $76.7 \%$ of the studied nurses had less than 5 years of experience. In addition, $83.3 \%$ of the studied nurses didn't attend any training courses regarding nasogastric tube care and its complications.

Table (2) clarifies that mean score of studied nurses' total knowledge about nasogastric tube was improved from $14.6833 \pm 5.85848$ pre guidelines implementation to $36.6833 \pm 2.04601$ post guidelines implementation. In addition, there were highly statistical differences between mean score of studied nurses' knowledge regarding nasogastric tube care pre guidelines implementation as compared to post guidelines implementation $(\mathrm{p}<0.001)$.

Table (3) clarifies that mean score of studied nurses' total practice about nasogastric tube was improved from $131.2833 \pm 12.85920$ pre guidelines implementation to $271.5667 \pm 8.19749$ post guidelines implementation. In addition, there were highly statistical differences between their mean scores of all total practice about nasogastric tube pre guidelines implementation as compared to post guidelines implementation $(\mathrm{p}<0.001)$.

Figure (1) demonstrates that $70 \%$ of studied nurses had unsatisfactory total knowledge score about nasogastric tube in pre guidelines implementation, where about post implementation $93.3 \%$ of them had satisfactory total knowledge score.

Figure (2) demonstrates that $53.3 \%$ of studied nurses had unsatisfactory total practice score about nasogastric tube in pre guidelines implementation, where about post implementation $95 \%$ of them had satisfactory total practice score.

Table (4) shows that, there was high significant statistical relation between studied nurses' total knowledge score and training courses regarding nasogastric tube care during preguidelines implementation as $(\mathrm{p}<0.001)$, as well as their total knowledge score and their educational level during pre-guidelines implementation as $(\mathrm{p}<0.05)$. While there was no significant statistical relation between studied nurses' total knowledge score and their demographic characteristics regarding age, sex and their years of experience pre as well as post guidelines implementation as ( $p>0.05)$.

Table (5) shows that there was high significant statistical relation between studied nurses' total practice score and their demographic characteristics regarding age and training courses regarding nasogastric tube care during preguidelines implementation as $(\mathrm{p}<0.001)$, as well as their total practice score, their educational level and their years of experience pre-guidelines implementation as $(\mathrm{p}<0.05)$. While there was no significant statistical relation between studied nurses' total practice score and their sex preguidelines implementation as well as their practice score and their demographic characteristics regarding age, sex, educational level, their years of experience and training courses regarding nasogastric tube care post guidelines implementation as ( $p>0.05)$.

Table (6) shows that there was high significant statistical positive correlation between studied nurses' total knowledge score and total practice score regarding nasogastric tube pre and post guidelines implementation as $(\mathrm{p}<0.001)$. 
Effect of Implementing Nursing Guidelines on Nurses' Performance Regarding Complications of Nasogastric Tube among Critically ill Patients

Table (1): Distribution of the studied nurses regarding their demographic characteristics (n=60)

\begin{tabular}{|c|c|c|}
\hline Variable & $\mathrm{No}=60$ & $\%$ \\
\hline \multicolumn{3}{|l|}{ Age in years } \\
\hline$<25$ & 40 & 66.7 \\
\hline $25-<35$ & 20 & 33.3 \\
\hline Mean \pm SD $\quad 23.82 \pm 2.20$ & & \\
\hline \multicolumn{3}{|l|}{ Sex } \\
\hline Female & 52 & 86.7 \\
\hline Male & 8 & 13.3 \\
\hline \multicolumn{3}{|l|}{ Educational level } \\
\hline Technical institute of nursing & 54 & 90.0 \\
\hline Bachelor of nursing & 6 & 10.0 \\
\hline \multicolumn{3}{|l|}{ Years of experience } \\
\hline$<5$ & 46 & 76.7 \\
\hline $5-10$ & 14 & 23.3 \\
\hline \multicolumn{3}{|l|}{ Training courses regarding NGT care } \\
\hline No & 50 & 83.3 \\
\hline Yes & 10 & 16.7 \\
\hline
\end{tabular}

Table (2): Mean and standard deviation of studied nurses' knowledge score about nasogastric tube pre and post guidelines implementation $(n=60)$

\begin{tabular}{|c|c|c|c|c|c|c|}
\hline \multirow[t]{2}{*}{ Nurses' knowledge } & \multicolumn{2}{|c|}{$\overline{\overline{\text { Pre }}}$} & \multicolumn{2}{|c|}{$\overline{\text { Post }}$} & \multirow[t]{2}{*}{ t test } & \multirow[t]{2}{*}{ p-value } \\
\hline & Mean & \pm SD & Mean & \pm SD & & \\
\hline Definition of nasogastric tube & 2.4667 & 1.2550 & 4.6667 & .62887 & 13.249 & $.000 *$ \\
\hline $\begin{array}{l}\text { Purpose and indications of nasogastric tube } \\
\text { insertion }\end{array}$ & .8333 & .37582 & 1.9167 & .27872 & 19.813 & $.000 * *$ \\
\hline Contraindications of nasogastric tube insertid & .6667 & .85701 & 1.8667 & .34280 & 10.813 & $.000 * *$ \\
\hline $\begin{array}{l}\text { Preparation and feeding administration throu } \\
\text { nasogastric tube }\end{array}$ & 3.0833 & .99646 & 10.4333 & .99774 & 48.396 & $.000 * *$ \\
\hline $\begin{array}{l}\text { Medication administration through nasogastr } \\
\text { tube }\end{array}$ & .3667 & .68807 & 2.0000 & .00000 & 18.387 & $.000 * *$ \\
\hline Complications related to nasogastric tube & 7.2667 & 3.3082 & 15.8000 & 1.29928 & 22.961 & $.000 * *$ \\
\hline Total knowledge & 14.683 & 5.8584 & 36.6833 & 2.04601 & 36.817 & $.000^{* * *}$ \\
\hline
\end{tabular}

Table (3): Mean and standard deviation of studied nurses' total practice about nasogastric tube pre and post guidelines implementation $(n=60)$

\begin{tabular}{|c|c|c|c|c|c|c|}
\hline \multirow{2}{*}{\begin{tabular}{|l|} 
Practice about \\
nasogastric tube
\end{tabular}} & \multicolumn{2}{|c|}{ Pre } & \multicolumn{2}{|c|}{$\overline{\text { Post }}$} & \multirow[t]{2}{*}{ t test } & \multirow[t]{2}{*}{ p-value } \\
\hline & Mean & \pm SD & Mean & \pm SD & & \\
\hline Total practice & 131.283 & 12.8590 & 271.567 & 8.19749 & 108.041 & $.000 * *$ \\
\hline & \multicolumn{3}{|c|}{$1 0 0 . 0 \longdiv { 9 3 . 3 }$} & \multirow{7}{*}{$\begin{array}{l}\text { Satisfactory } \\
\text {; Unsatisfactory }\end{array}$} & & \\
\hline & 80.0 & 70.0 & & & & \\
\hline & 60.0 & 3 & & & & \\
\hline & 40.0 & 3 & & & & \\
\hline & 20 & 8 & & & & \\
\hline & $\begin{array}{r}20.0 \\
0.0\end{array}$ & 2 & & & & \\
\hline & \multicolumn{2}{|c|}{ Pre-program } & gram & & & \\
\hline
\end{tabular}

Figure (1): Percentage distribution of studied nurses' knowledge score about nasogastric tube pre and post guidelines implementation. 


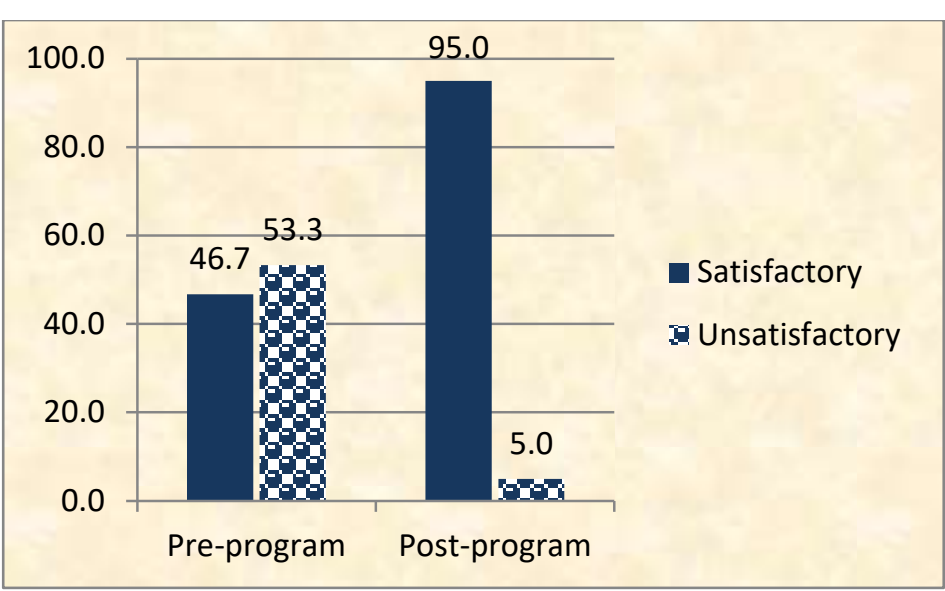

Figure (2): Percentage distribution of studied nurses' total practice score about nasogastric tube pre and post guidelines implementation.

Table (4): Relation between studied nurses' total knowledge score and their demographic characteristics $(\mathbf{n}=\mathbf{6 0})$

\begin{tabular}{|c|c|c|c|c|c|c|c|c|c|c|c|c|}
\hline \multirow{4}{*}{$\begin{array}{l}\text { Demographic } \\
\text { characteristics }\end{array}$} & \multicolumn{12}{|c|}{ Nurses' total knowledge } \\
\hline & \multicolumn{4}{|c|}{ Pre } & \multirow{3}{*}{$\mathbf{X}^{2}$} & \multirow{3}{*}{ p-valu } & \multicolumn{4}{|c|}{ Post } & \multirow{3}{*}{$\mathbf{X}^{2}$} & \multirow{3}{*}{ p-valu } \\
\hline & \multicolumn{2}{|c|}{$\begin{array}{l}\text { Un satisfied } \\
(n=42)\end{array}$} & \multicolumn{2}{|c|}{$\begin{array}{l}\text { Satisfied } \\
(\mathrm{n}=18)\end{array}$} & & & \multicolumn{2}{|c|}{$\begin{array}{l}\text { Un satisfied } \\
(n=4)\end{array}$} & \multicolumn{2}{|c|}{\begin{tabular}{|l|} 
Satisfied \\
$(\mathbf{n = 5 6})$
\end{tabular}} & & \\
\hline & No & $\%$ & No & $\%$ & & & No & $\%$ & No & $\%$ & & \\
\hline$<25$ & 31 & 73.8 & 9 & 50.0 & 3.21 & 0.073 & 4 & 100. & 36 & 64.3 & 2.14 & 0.143 \\
\hline $25-<35$ & 11 & 26.2 & 9 & 50.0 & & & 0 & 0.0 & 20 & 35.7 & & \\
\hline \multicolumn{13}{|l|}{ Sex } \\
\hline Female & 36 & 85.7 & 16 & 88.9 & 0.11 & 0.74 & 3 & 75.0 & 49 & 87.5 & 0.5 & 0.477 \\
\hline Male & 6 & 14.3 & 2 & 11.1 & & & 1 & 25.0 & 7 & 12.5 & & \\
\hline \multicolumn{13}{|l|}{ Educational level } \\
\hline $\begin{array}{l}\text { Technical institu } \\
\text { of nursing }\end{array}$ & 41 & 97.6 & 13 & 72.2 & 9.03 & 0.003 & 4 & 100. & 50 & 89.3 & 0.47 & 0.49 \\
\hline $\begin{array}{l}\text { Bachelor of } \\
\text { Nursing }\end{array}$ & 1 & 2.4 & 5 & 27.8 & & & 0 & 0.0 & 6 & 10.7 & & \\
\hline \multicolumn{13}{|c|}{ Years of experience } \\
\hline$<5$ & 32 & 76.2 & 14 & 77.8 & 0.018 & 0.894 & 4 & 100. & 42 & 75.0 & 1.304 & 0.253 \\
\hline $5-10$ & 10 & 23.8 & 4 & 22.2 & & & 0 & 0.0 & 14 & 25.0 & & \\
\hline \multicolumn{13}{|c|}{ Training courses regarding NGT care } \\
\hline No & 40 & 95.2 & 10 & 55.6 & 14.28 & $.000^{*}$ & 4 & 100. & 46 & 82.1 & 0.85 & 0.355 \\
\hline Yes & 2 & 4.8 & 8 & 44.4 & & & 0 & 0.0 & 10 & 17.9 & & \\
\hline
\end{tabular}


Effect of Implementing Nursing Guidelines on Nurses' Performance Regarding Complications of Nasogastric Tube among Critically ill Patients

Table (5): Relation between studied nurses' total practice score and their demographic characteristics $(\mathbf{n}=60)$

\section{Nurses' total practice}

\begin{tabular}{|c|c|c|c|c|c|c|c|c|c|c|c|c|}
\hline \multirow{3}{*}{$\begin{array}{l}\text { Demographic } \\
\text { characteristics }\end{array}$} & \multicolumn{12}{|c|}{ Nurses' total practice } \\
\hline & \multicolumn{4}{|c|}{ Pre } & \multirow{3}{*}{$\mathbf{X}^{2}$} & \multirow{3}{*}{ p-valu } & \multicolumn{4}{|c|}{ Post } & \multirow{3}{*}{$\mathbf{X}^{2}$} & \multirow{3}{*}{ p-val } \\
\hline & \multicolumn{2}{|c|}{$\begin{array}{c}\text { Un satisfied } \\
(n=32)\end{array}$} & \multicolumn{2}{|c|}{$\begin{array}{c}\text { Satisfied } \\
(n=28)\end{array}$} & & & \multicolumn{2}{|c|}{$\begin{array}{c}\text { Un satisfied } \\
(\mathbf{n}=3)\end{array}$} & \multicolumn{2}{|c|}{$\begin{array}{c}\text { Satisfied } \\
(\mathrm{n}=57)\end{array}$} & & \\
\hline Age & No & $\%$ & $\mathrm{No}$ & $\%$ & & & No & $\%$ & No & $\%$ & & \\
\hline$<25$ & 28 & 87.5 & 12 & 42.9 & 13.39 & $.000 * *$ & 3 & 100.0 & 37 & 64.9 & 1.57 & 0.209 \\
\hline $25-<35$ & 4 & 12.5 & 16 & 57.1 & & & 0 & 0.0 & 20 & 35.1 & & \\
\hline \multicolumn{13}{|l|}{ Sex } \\
\hline Female & 28 & 87.5 & 24 & 85.7 & 0.04 & 0.839 & 3 & 100.0 & 49 & 86.0 & 0.48 & 0.486 \\
\hline Male & 4 & 12.5 & 4 & 14.3 & & & 0 & 0.0 & 8 & 14.0 & & \\
\hline \multicolumn{13}{|c|}{ Educational level } \\
\hline $\begin{array}{l}\text { Technical institu } \\
\text { of nursing }\end{array}$ & 32 & 100.0 & 22 & 78.6 & 7.61 & $.006 *$ & 3 & 100.0 & 51 & 89.5 & 0.35 & 0.554 \\
\hline $\begin{array}{l}\text { Bachelor of } \\
\text { Nursing }\end{array}$ & 0 & 0.0 & 6 & 21.4 & & & 0 & 0.0 & 6 & 10.5 & & \\
\hline \multicolumn{13}{|c|}{ Years of experience } \\
\hline$<5$ & 28 & 87.5 & 18 & 64.3 & 4.49 & $.034 *$ & 3 & 100.0 & 43 & 75.4 & 0.96 & 0.327 \\
\hline $5-10$ & 4 & 12.5 & 10 & 35.7 & & & 0 & 0.0 & 14 & 24.6 & & \\
\hline \multicolumn{13}{|c|}{ Training courses regarding NGT care } \\
\hline No & 32 & 100.0 & 18 & 64.3 & 13.71 & $.000 * *$ & 3 & 100.0 & 47 & 82.5 & 0.63 & 0.427 \\
\hline Yes & 0 & 0.0 & 10 & 35.7 & & & 0 & 0.0 & 10 & 17.5 & & \\
\hline
\end{tabular}

Table (6): Correlation between studied nurses' total knowledge score and total practice score regarding nasogastric tube pre and post guidelines implementation $(n=60)$.

\begin{tabular}{||c|c|c|c|c|}
\hline \multirow{3}{*}{ Total practice } & \multicolumn{3}{|c|}{ Total Knowledge } \\
\cline { 2 - 5 } & \multicolumn{2}{|c|}{ Pre } & \multicolumn{2}{c|}{ Post } \\
\cline { 2 - 5 } & r & $0.000^{* *}$ & 0.73 & $0.000^{* *}$ \\
\cline { 2 - 6 } & 0.88 & r & p-value & 0.73 \\
& &
\end{tabular}

\section{Discussion}

Inserting nasogastric tube is very important to give essential nutrients required to body growth, maintain GIT function, avoid malnutrition and dehydration. If the NGT is not monitored regularly by nurses and giving good routine care and proper care during complications, it can lead to serious harm including aspiration pneumonia, infection, gastrointestinal disorders, mechanical and metabolic complications (Rowat, Graham \& Dennis, 2018). 
The results of the present study revealed that two thirds of the studied nurses' age was less than 25 years old. From the researcher's point of view these results may be due to the studied nurses who were working in critical area (ICU) are recently graduated and young age to be suitable with workload. These results agreed with Babapour et al., (2016) in his study entitled "Nurses' practice about performance of nasogastric tube feeding in intensive care unit" whose results revealed that half of the nurses' age was less than 30 years old.

Also these results agreed with Al-Qalah \& Alrubaiee, (2020) in their study entitled "Intensive care nurses' knowledge of enteral nutrition at public hospitals in Sana'a, Yemen: a cross-sectional survey" whose results revealed that almost half of the nurses' age ranged from 20 to 25 years. These results disagreed with Cumber, Akama \& Nkongho, (2016) in their study entitled "Approaches Used by Nurses in the Care of Patients with Nasogastric Intubation (NG Tubes) at the Laquintinie Hospital Douala Cameroon" whose results revealed that total nurses' age range from 30 and above.

As regard to sex, the current study revealed that most of nurses were females. From the researcher's point of view these results may be due to most nurses who were working in Benha University Hospital were females. This result is compatible with Chen, Lee \& Fang, (2018) in their study entitled "Improving Nurse Skill of Medication Administration via Enteral Feeding Tube" whose results revealed that all of the nurses' samples were females. This result disagreed with Aziz \& Ali, (2020) in their study entitled "Determination of the Critical Care Nurses Knowledge Toward Enteral Tube Feeding in AL-Hilla Teaching Hospitals (Interventional study)" whose results revealed that most of the study samples were males.
As regard to educational level, the current study revealed that the majority of the studied nurses had technical institute of nursing. From the researcher's point of view these results may be due to most bachelor nurses in the governmental hospitals are working as nursing supervisor or head nurse not bedside nurse, but technical nurses are working as bedside nurse. This result agreed with Mahmoud, (2018) in his study entitled "Nurses' Performance Regarding Nasogastric Tube Feeding Among Critically Ill Patients" whose results revealed that, near half of the nurses under study were having technical institute degree.

This result disagreed with Khani, Vazin \& Shafiekhani, (2016) in their study entitled "Evaluating knowledge, attitude and practice of intensive care unit nurses in administering medications via enteral tubes" whose results revealed that the majority of the nurses had bachelor's degree in nursing.

As regard to nurses' years of experience, the current study revealed that three quarters of the studied nurses had less than 5 years of experience. From the researcher's point of view this finding may be due to most of the nurses under study were recently graduated and young ages. This result is in the same line with AlQalah \& Alrubaiee, (2020) whose results revealed that almost two-thirds of nurses had one to five years of working experience. This result was inconsistent with Huang et al., (2019) in their study entitled "Current status and influencing factors of barriers to enteral feeding of critically ill patients: A multicenter study" whose results revealed that half of nurses had 610 years of experience.

Finally regarding attendance of training courses regarding nasogastric tube care, the current study revealed that the majority of nurses didn't attend any training courses regarding 
nasogastric tube care. From the researcher's point of view this result may be due to those training courses specific to nasogastric tube weren't held at the hospital. This result agreed with AlHawaly, Ibrahim \& Qalawa, (2016)in their study entitled "Assessment of nurses' knowledge and performance regarding feeding patients with nasogastric tube in Ismailia General Hospital" whose results revealed that the nearly one third only of studied samples had training courses regarding nasogastric tube care. This result also agreed with Kalaldeh, (2017) in his study entitled "The influence of implementing nurse-led enteral nutrition guidelines on care delivery in the critically ill" whose results revealed that the majority of nurses didn't receive any training courses about enteral feeding.

The study revealed that there was an improvement in mean scores of studied nurses' total knowledge regarding nasogastric tube care post guidelines implementation compared to pre guidelines implementation. This finding consisted with Mahdy, Hamed \& Shehata, (2019) in their study entitled "Efficacy of Safety Measures and Discharge Planning Guidelines on Nurses for Enteral Nutrition of Comatose Patients" who stated that there was statistically significant difference were noted and a general improvement in mean nurses' knowledge results of nasogastric tube care from pre- to post-intervention.

The current study also revealed that there was high statistical significant improvement in mean scores of all total practice regarding nasogastric tube care and its complications post guidelines implementation compared to pre guidelines implementation. This finding supported by Ahmed et al., (2018) in their study entitled "Effect of Educational Nursing Guidelines Regarding Enteral Feeding on Nurses' Knowledge and Practices at Critical Care Units" who stated that there was a highly statistical significant difference in mean scores of all total practice regarding nasogastric tube pre and post implementation of educational guidelines.

The study revealed that post guidelines implementation the majority of studied nurses had satisfactory level of knowledge score regarding nasogastric tube and its complications. These reflect the success of the implementations of the nursing guidelines in achieving the research objectives. This finding supported by Kim \& Chang, (2019) in their study entitled "Implementing an educational program to improve critical care nurses' enteral nutritional support" who stated that most nurses had unsatisfactory knowledge level regarding nasogastric tube pre intervention guidelines however; post-intervention there was a significant improvement in nurses' knowledge level.

These findings also supported by ElMeanawi, (2017) in his study entitled "Impact of implementing an educational Program regarding Care of Nasogastric Tube Feeding on nurses knowledge and performance" who stated that the majority of the nurses had satisfied knowledge about nasogastric tube feeding care after they provided educational program and comparing to the majority of them had unsatisfied knowledge before this educational program.

The study also revealed that more than half of studied nurses had unsatisfactory level of practice score regarding nasogastric tube and its complications pre guidelines implementation; while post guidelines implementation, there was an improvement in total nurses' practices score; this may be due to poor skills, workload, lack of concentration and lack of experience. While post guidelines implementation, there was an improvement in total nurses' practices score which reflects the positive effect of nursing guidelines on nurses' practice during caring for 
patients with nasogastric tube and its complications.

These findings was supported by Chang et al., (2015) who noted that most nurses had a preintervention level of unsatisfactory practice regarding nasogastric tube care. However, the majority of nurses had a level of good practice after implementation of the guidelines.

Regarding the relation between studied nurses' total knowledge score and their demographic characteristics, the current study showed that there was statistical significant relation between studied nurses' total knowledge score and their educational level as well as training courses regarding nasogastric tube care pre-guidelines implementation. From the researcher's point of view these results may be due to nurses who attended previous training courses about nasogastric tube have more knowledge than nurses who didn't attend previous training courses about it and nurses who have high educational level have more knowledge at pre-guidelines implementation than others who have lower levels of education.

These findings agreed with Mahdy, Hamed \& Shehata, (2019) whose result showed that there was significant relation between nurses' knowledge and their demographic characteristics regarding training courses about nasogastric tube care and their educational level during preguidelines implementation.

These findings disagreed with Bayat et al., (2016) in their study entitled "Knowledge assessment and comparing the performance of intensive care unit nurses in regard to tube feeding with existing standards in educational and treatment centers of Qom University of Medical Sciences" whose result show that there was highly statistically significant relation between the nurses' level of knowledge and years of experience pre guidelines implementation.

The study also showed that there was no statistical significant relation between studied nurses' total knowledge score and their demographic characteristics regarding age, sex, educational level, their years of experience and training courses regarding nasogastric tube care post guidelines implementation. These findings agreed with Ahmed et al., (2018) whose result show that nurses' age, sex and years of experience were found to be not significantly related with nurses' knowledge at post implementation of educational guidelines.

Regarding the relation between studied nurses' total practice score and their demographic characteristics, the current study showed that there was statistical significant relation between studied nurses' total practice score and their demographic characteristics regarding age, their educational level, their years of experience and training courses about nasogastric tube care preguidelines implementation.

While there was no statistical significant relation between studied nurses' total practice score and their sex pre guidelines implementation. From the researcher's point of view these results may be due to the fact that nursing education, training courses and years of experience could improve level of practical skills among the studied nurses, while sex has no significant statistical relation with practical scores may be related to the fact that the majority of the studied nurses were females.

The study also revealed that there was no statistical significant relation between studied nurses' total practice score and their demographic characteristics regarding age, sex, educational level, their years of experience and training courses regarding nasogastric tube care post guidelines implementation. From the researcher's 
point of view these results may be due to most studied nurses' practice score was improved after guidelines implementation.

These finding agreed with Mahmoud, (2018) whose result show that there was significant relation between nurses' level of practice and their age and years of experience pre guidelines implementation.

implementation. But agreed with him in there was no statistical significance difference between nurses' practice and their age groups and educational level and years of experience post program implementation.

The study revealed that there was high statistical significant positive correlation between studied nurses' total knowledge score and total practice score pre and post guidelines implementation. From the researcher's point of view these result may be due to the knowledge acquired by studied nurses help them to perform practical skills after understanding the scientific knowledge background about them.

These findings agreed with El-Meanawi, (2017) whose result showed that there was a positive correlation between nurse's knowledge and practice in period of pre and post providing them health education program, this strong correlation between nurses' knowledge and practice is highly expectable, basic knowledge about nasogastric tube is essential for nursing practice and optimal outcomes for patients.

\section{Conclusions}

-The majority of the studied nurses had unsatisfactory level of performance (knowledge and practice) regarding complications of nasogastric tube among critically ill patients pre guidelines implementation, while the majority of the studied nurses had high statistically
These finding disagreed with Bedier, ELAta \& Shehab, (2016) in their study entitled "Effect of Educational Program on Nurses' Practice Related to Care of Patients Undergoing Nasogastric Tube Feeding" whose result showed that there was no statistical significance difference between nurses' practice and their age groups and educational level preprogram

significant improvement in their performance post guidelines implementation that supported the study hypothesis.

\section{Recommendations}

-Conducting continuous training courses for nurses about nasogastric tube care and its complications among critically ill patients.

-Continuous evaluation for nurses' performance regarding complications of nasogastric tube among critically ill patients.

-Replication of the study using a larger probability sample from different geographical areas to attain more generalizable results.

-Providing educational program for nurses about prevention and management of nasogastric tube complications among critically ill patients.

\section{References:}

Abdullah, M., Mohammed, W., \& Ismail, M. (2014). Nurses' knowledge and practices about administration of medications via nasogastric tube among critically ill patients. Journal of Education and Practice, 5(1), 147-159.

\footnotetext{
Ahmed, F. A. H. M., Ahmed, O. A. E., Abd, E., Albitar, E., \& Ghoneim, S.
}

E. S) 2018 ).Effect of Educational Nursing Guidelines Regarding Enteral Feeding on Nurses' Knowledge and Practices at Critical Care Units .IOSR Journal of Nursing and Health Science (IOSR-JNHS), 7(5), 69-75. 
Al-Hawaly, M., Ibrahim, M. H., \& Qalawa, S. A. (2016). Assessment of nurses 'knowledge and performance regarding feeding patients with nasogastric tube in Ismailia General Hospital. Med J Cairo Univ, 84, 99-105.

Al-Qalah, T. A. H., \& Alrubaiee, G. G. (2020). Intensive care nurses' knowledge of enteral nutrition at public hospitals in Sana'a,Yemen: a cross-sectional survey. F1000Research, 9(759), 759.

Aziz, K. M., \& Ali, S. A. (2020).Determination of the Critical Care Nurses Knowledge Toward Enteral Tube Feeding in AL-Hilla Teaching Hospitals(Interventional study). Medico Legal Update, 20(1), 1153-1157.

Babapour, S. K., Esmaeili, R., Esteki, T., Naderiravesh, N., Pourhoseingholi, M. A., \& Marzangu, S. M. H. (2016). Nurses' practice about performance of nasogastric tube feeding in intensive care unit. International Journal of Advanced Biotechnology and Research, 7, 15851594

Bayat, Z. S., Ahmadli, R., Maleki, M., Jambarsang, S., \& Dabirian, A. (2016).

Knowledge assessment and comparing the performance of intensive care unit nurses in regard to tube feeding with existing standards in educational and treatment centers of Qom University of Medical Sciences, Iran. Qom University of Medical Sciences Journal, 10(3) 4554.

Bedier, N. A., EL-Ata, A. B. A., \& Shehab, M. S. (2016). Effect of Educational Program on Nurses' Practice Related to Care of Patients Undergoing Nasogastric Tube Feeding. International Journal of Caring Sciences, 9(2), 432.

Blumenstein, I., Shastri, Y. M., \& Stein, J. (2014). Gastroenteric tube feeding techniques, problems and solutions. World journal of gastroenterology:WJG, 20(26), 8505 ISO 690

Chang, S. C., Huang, C. Y., Lin, C. H., Tu, S. L., Chao, M. S., \& Chen, M. H. (2015). The effects of systematic educational interventions about nasogastric tube feeding on caregivers' knowledge and skills and the incidence of feeding complications. Journal of clinical nursing, 24(1112), 1567-1575.

Chen, C. J., Lee, H. F., \& Fang, Y. C. (2018). Improving Nurse Skill of Medication Administration via Enteral Feeding Tube. Nur Primary Care, 2(5), 1-5.

Cooper, K., Gosnell, K., (2018). Foundations and Adult Health Nursing Elsevier Health Sciences 8th Edition p355

Cumber, S. N., Akama, N. M., \& Nkongho, L. A. M. (2016). Approaches Used by Nurses in the Care of Patients with Nasogastric Intubation (NG Tubes) at the Laquintinie Hospital Douala Cameroon. Journal of Family Medicine and Health Care, 2(4), 30-35.

El-Meanawi, N. H. K. K. (2017). Impact of implementing an educational Programme regarding Care of Nasogastric Tube Feeding on nurses knowledge and performance. IOSR J Nurs Health Serv, 6(1), 101-109.

Huang, J., Yang, L., Zhuang, Y., Qi, H., Chen, X., \& Lv, K. (2019). Current

status and influencing factors of barriers to enteral feeding of critically ill patients: A multicenter study. Journal of clinical nursing, 28(3-4), 677-685.

Jamshidi, S., Hejazi, N., \& Mazloom, Z. (2020). ICU Nurses' Knowledge about Enteral Feeding in Critically Ill Patients in Nemazee 
Hospital in Shiraz Iran. International Journal of Nutrition Sciences, 5(1), 19-23.

Kalaldeh, M. A. (2017). The influence of implementing nurse-led enteral nutrition guidelines on care delivery in the critically ill: a cohort study. Gastrointestinal Nursing, 15(6), 3442.

Karem, M. A., Mahmood, Y. N., Jameel, A. S., \& Ahmad, A. R. (2019). The effect of job satisfaction and organizational commitment on nurses' performance. Journal of Humanities and Social Sciences Reviews. eISSN, 2395-6518.

Khani, J., Vazin, A., \& Shafiekhani, M. (2016). Evaluating knowledge, attitude and practice of intensive care unit nur in administering medications via

enteral tubes.Trends in Pharmaceutical Sciences, 2(3), 195-204.

Kim, H., \& Chang, S. J. (2019). Implementing an educational program to improve critical care nurses' enteral nutritional support. Australian Critical

Care, 32(3), 218-222.

Koontalay, A., Sangsaikaew, A., \& Khamrassame, A. (2020). Effect of a Clinical Nursing Practice Guideline of Enteral Nutrition Care on the Duration of Mechanical Ventilator for Critically Ill Patients. Asian Nursing Research, 14(1), 17-23.

Lewis S. L., Bucher, L , Heitkemper, M. M., Harding M. M., Kwong, J.,

Roberts,D. (2017) Medical-Surgical Nursing - EBook: Assessment and

Management of Clinical Problems, nutritional problem, 10th Edition, Elsevier Health Sciences,chapter39,p867
Mahdy, A. Y., Hamed, L. A., \& Shehata, A. A. M. (2019). Efficacy of Safety Measures and Discharge Planning Guidelines on Nurses for Enteral Nutrition of Comatose Patients . International Journal of Novel Research in Healthcare and Nursing, 6(3) 220-231.

Mahmoud, A. M. (2018). Nurses' Performance Regarding Nasogastric Feeding Among Critically Ill Patients .IOSR Journal of Nursing and Health Science (IOSR-JNHS) e-ISSN: 23201959.p- ISSN: 2320-1940, 7(1) 30- 36.

Metwaly, E. A., Mohammed, E. H., \& Mohammed, M. A. E. (2013). Nurses' Performance Regarding Nasogastric Tube Feeding in Intensive Care Units. Zagazig Nursing Journal, 9(1), 69-86

Mooi, N. M. (2018). Knowledge of intensive care nurses regarding the monitoring of early enteral nutrition. Africa Journal of Nursing and Midwifery, 20(2), 1- 14.

Rezaei, F., Savadi, M. H., Douki, M. F., \& Shiadeh, F. S. A. (2018). Comparison

of Enteral Feeding Implementation with Standards in Educational Centers, Selected Therapeutics in Babol University of Medical Sciences. International Journal of Ayurvedic Medicine, 9(2), 106-110.

Rowat, A. M., Graham, C., \& Dennis, M. (2018). Study to determine the likely accuracy of $\mathrm{pH}$ testing to confirm nasogastric tube placement. BMJ open gastroenterology, 5(1).

Willihnganz ,M., Clayton B, D., (2016). Basic Pharmacology for Nurses. 17th ed .

Indian: Elsevier Health Science; ISBN 978032355061. 492. 
Xu, L. C., Huang, X. J., Lin, B. X., Zheng, J.

Y., \& Zhu, H. H. (2020). Clinical nurses'

nasogastric feeding practices in adults: a

multicenter cross-sectional survey in

China. Journal of International Medical

Research, 48(4), 0300060520920051. 
تأثير تطبيق الإرشادات التمريضية على أداء الممرضين تجاه مضاعفات الأنبوب الأنفي المعدي

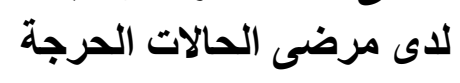

فاطمة محمد عطية محمد- منال حامد محمود- نهال محمود أبو الفضل

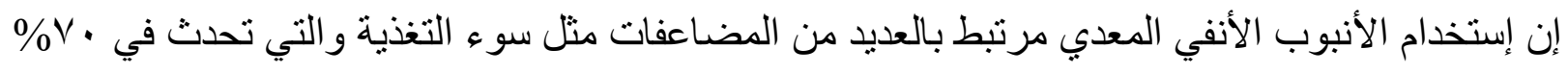

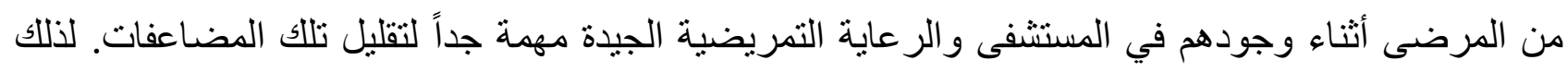

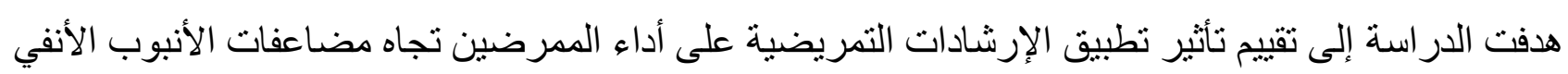

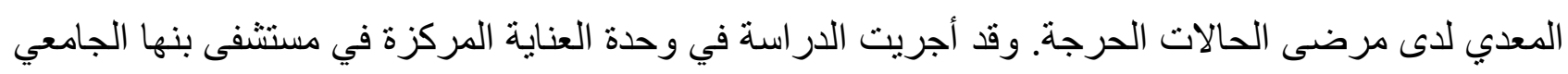

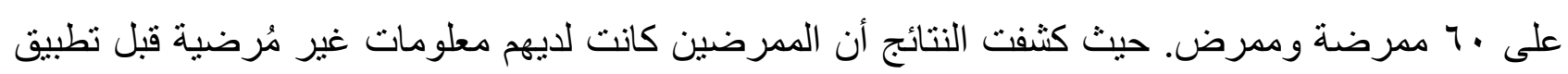

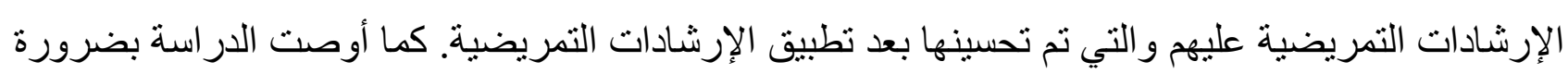
عمل تقييم مستمر لأداء الممرضين تجاه الأنبوب الأنفي المعدي ومضاعفاته وذللك لتحسين أدائهر. 